\title{
The Effect of the Host's Iron Status on Tuberculosis
}

\author{
Johan R. Boelaert, ${ }^{1}$ Stefaan J. Vandecasteele, ${ }^{1}$ Rui Appelberg, ${ }^{2}$ and Victor R. Gordeuk ${ }^{3}$ \\ ${ }^{1}$ Internal Medicine, Unit of Renal and Infectious Diseases, Algemeen Ziekenhuis St-Jan, Brugge, Belgium; ${ }^{2}$ Institute for Molecular and Cell Biology and Instituto \\ de Ciências Biomédicas de Abel Salazar, University of Porto, Porto, Portugal; ${ }^{3}$ Center for Sickle Cell Disease, Howard University, Washington, DC
}

Several lines of evidence have suggested that iron is critical for Mycobacterium tuberculosis growth in macrophages. Macrophage iron loading in patients with African iron overload increases the risk of tuberculosis (TB) and may worsen TB outcome. Likewise, macrophage iron loading may contribute to an increased predisposition toward TB in HIV infection. Human genetic disorders or variations may increase the risk of TB or worsen its outcome through macrophage iron loading, including the haptoglobin 2-2 phenotype, NRAMP1 polymorphisms (at least in Africans and Asians), and possibly ferroportin 1 mutations, but not HFE hemochromatosis. Thus, the host's iron status may be an important yet underevaluated factor in TB prevention and therapy and in TB vaccine design.

In this review of the relationship between tuberculosis and iron, we wish to bridge biological and clinical issues, emphasizing human conditions that might result in macrophage iron loading. The degree of evidence from clinical studies is rated by grades: 1 (randomized controlled), 2 (nonrandomized controlled), and 3 (uncontrolled studies, descriptive studies, and expert opinion).

We searched in Medline, without date restriction, for the terms "mycobacterium," "tuberculosis," "iron," and "macrophage" and searched for them in interaction with "immune reaction"; "immunology"; "Th1, Th2, cytokines"; "African iron overload"; "malaria"; "plasmodium"; "hemozoin"; "tobacco"; "smoking"; "alcohol”; "etha-

Received 9 October 2006; accepted 9 January 2007; electronically published 4 May 2007.

Potential conflicts of interest: none reported.

Financial support: National Heart, Lung, and Blood Institute (grant 2 R25 HL003679-08); Howard University; National Center for Research Resources, National Institutes of Health (General Clinical Research Center grant 2MOI RR10284-10).

Reprints or correspondence: Dr. Johan R. Boelaert, Internal Medicine, Unit of Renal and Infectious Diseases, AZ St-Jan, Ruddershovelaan 10, B-8000 Brugge, Belgium (Johan .R.Boelaert@okynet.be).

The Journal of Infectious Diseases 2007; 195:1745-53 (C) 2007 by the Infectious Diseases Society of America. All rights reserved.

0022-1899/2007/19512-0004\$15.00

DOI: $10.1086 / 518040$ nol”; "alcoholism"; “HIV”; “AIDS"; "genetics"; "hemochromatosis"; "HFE"; "haptoglobin"; "NRAMP1"; "SLC11A1"; "p-aminosalicylic acid"; "isoniazid"; "ethambutol"; "tuberculosis vaccine"; and "BCG." Because of space limitations, only those articles considered by all authors to be most relevant were retained.

\section{MACROPHAGE IRON HOMEOSTASIS}

As shown in figure 1 and as reviewed by others [1], macrophages engulf and digest senescent erythrocytes, degrade heme, and, thus, accumulate iron into the cytosol. Cytosolic iron may be partly incorporated into ferritin, but normally most of it egresses the macrophage to be bound by plasma transferrin for delivery to bonemarrow erythroid precursors. Macrophage iron export is mediated by ferroportin 1 (also termed "SLC40A1"), the receptor for hepcidin, a peptide secreted by the liver in response to inflammation or excess iron [2]. The hepcidin-ferroportin 1 complex is internalized and degraded in lysosomes, locking iron inside macrophages (as well as enterocytes) [2]. Erythrophagocytosis and subsequent iron export via ferroportin 1 constitutes the major iron flux in- volving macrophages. Iron also enters macrophages via the transferrin-transferrin receptor (TfR) pathway [1], the binding of ferric lactoferrin (hololactoferrin) to lactoferrin receptors [3], and the binding of hemoglobin-haptoglobin (Hp) to the macrophage $\mathrm{CD} 163$ receptor during hemolysis [4]; these pathways may assume greater importance depending on the specific macrophage location and functional specialization. Inflammation induces macrophage iron retention, as observed in patients with inflammation, whose blood monocytes show down-regulated ferroportin 1 expression that correlates with increased ferritin levels and mirrors increased urinary hepcidin concentrations (used as surrogate for plasma hepcidin) [5].

\section{ACQUISITION OF IRON BY MYCOBACTERIUM TUBERCULOSIS}

Importance of iron acquisition. As confirmed in patient alveolar macrophages, M. tuberculosis resides within the macrophage phagosome and prevents phagosome-lysosome fusion by an unclear mechanism [6, 7]. The M. tuberculosiscontaining phagosome has early endoso- 


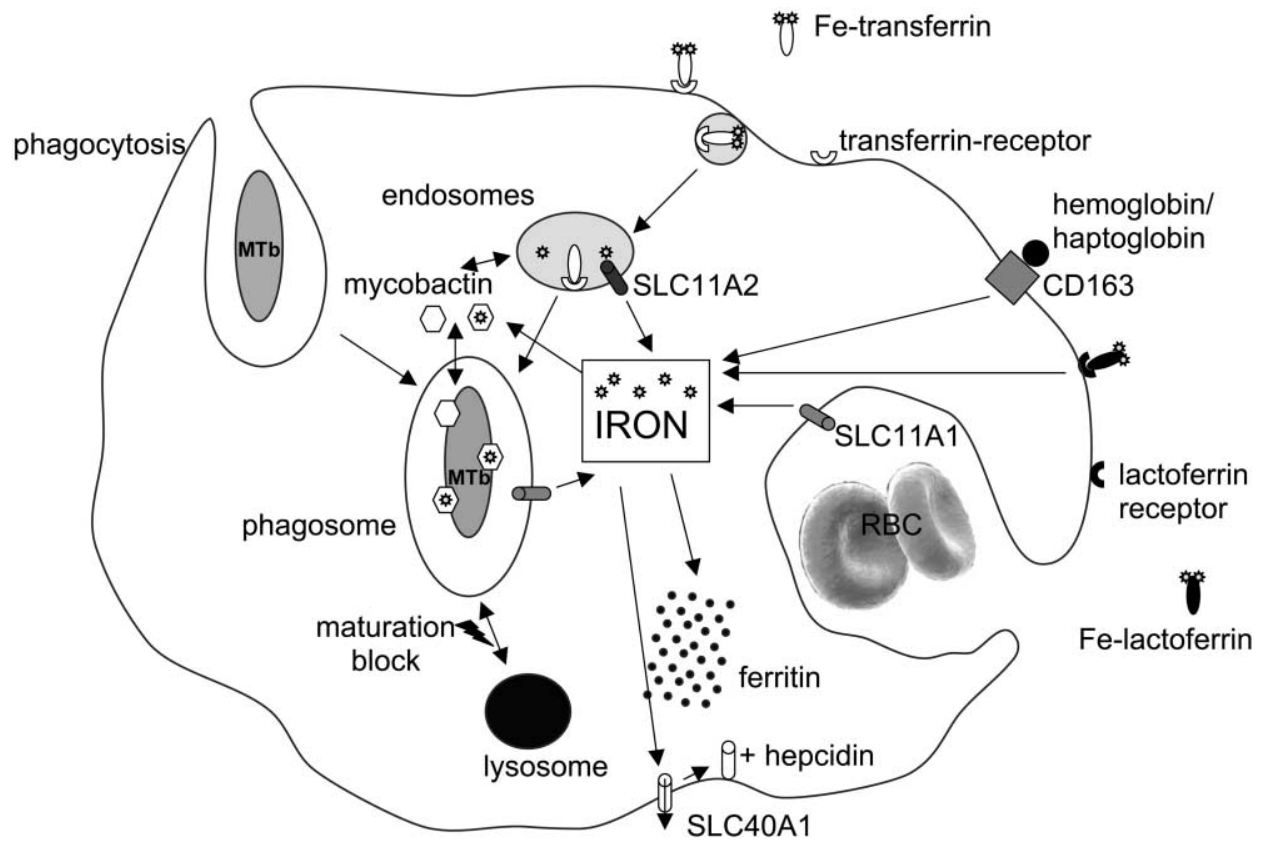

Figure 1. Schematic representation of a Mycobacterium tuberculosis (MTb)-infected macrophage and its iron metabolism. MTb resides in an early phagosome, whose maturation to the late phagosome and phagolysosome stages is blocked and whose acidification is limited. Macrophage iron sources are: (1) heme-bound iron from red blood cells (RBCs, main source; the presence of SLC11A1/NRAMP1 within the RBC vacuole is still speculative) and from the hemoglobin-haptoglobin complex, taken up via the hemoglobin scavenger receptor CD163; and (2) iron bound to transferrin and lactoferrin. On release into the cytoplasm, iron can be incorporated into proteins, including the iron-storage protein ferritin, and its presence can be sensed by iron regulatory proteins (not shown). Iron is exported from the cell via SLC40A1 (ferroportin 1), at least when the serum concentration of hepcidin is low to normal; when serum hepcidin is high (as occurs in iron excess or in the presence of inflammation), hepcidin binds to ferroportin 1, the complex is internalized, and iron export is inhibited, resulting in the iron-retention characteristic of inflammation. Binding of iron-bound lactoferrin to its cellular receptor and subsequent iron release are ill defined. Serum iron-bound transferrin binds to the transferrin receptor on the cell surface, and the complex is internalized in the early endosome, where low pH separates iron from the complex, allowing the iron-free complex to recycle to the cell surface and iron to be released into the cytoplasm via SLC11A2 (DMT1). Within its phagosome, MTb can capture iron either from cytoplasmic sources (represented by the central rectangle) or from the transferrin/transferrin receptor complex by interacting with the early endosome. These captures are made possible by a dual mycobacterial siderophore system made of mycobactins. These consist in a water-soluble carboxymycobactin T, which is thought to vehicle iron to a lipophilic mycobactin T associated with the MTb cell wall. Some evidence suggests that phagosomal iron can be pumped out via the SLC11A1 (NRAMP1) efflux pump.

mal characteristics, interacts with early endosomes, and does not acidify below $\mathrm{pH}$ 6.3-6.5 [6, 7]. M. tuberculosis perceives the phagosome as a low-iron environment $[8$, 9]: hence the importance of iron-acquisition strategies in the face of the host's iron-withholding mechanisms $[9,10]$. Iron limitation induces at least $35 \mathrm{M}$. tuberculosis genes, including $m b t A-J$, which encode enzymes involved in siderophore biosynthesis, but represses $b f r A$, which encodes an iron-storing bacterioferritin [8]. Consistent with the concept of iron restriction during immune control of M. tuberculosis replication, $m b t B$ mRNA levels increase and $b f r B$ mRNA levels decrease several weeks after infection in mice $[11,12]$.

Tools used. Salicylate-derived $M$. tuberculosis siderophores, termed "mycobactins," are composed of 2 entities: hydrophilic mycobactin T (carboxymycobactin) and the more lipophilic M. tuberculosis cell wall-associated mycobactin $\mathrm{T}$, which appears to transfer iron captured by hydrophilic mycobactin across the mycobacterial cell wall [13]. An M. tuberculosis strain with a deleted $m b t B$ gene has interrupted mycobactin synthesis, impaired intraphagosomal iron acquisition, and retarded growth within THP-1 cells $[14,15]$. The product of another M. tu- berculosis gene, ideR, represses $m b t$ expression in an iron-dependent manner but activates $b f r A[16,17]$. Two other genes, irt $A$ and $\operatorname{irt} B$ (for iron-regulated transporters $A$ and $B$ ), encode enzymes that possibly translocate Fe-carboxymycobactin into the mycobacterial cytoplasm independently of mycobactin [18].

Host iron sources. M. tuberculosisscavenges iron from the host-cell transferriniron acquisition pathway [6] (figure 1). Mycobactins are able to extract iron from exogenous holotransferrin $[6,19]$. Phagosomes containing live $M$. tuberculosis interact with early endosomes to which holotransferrin traffics (figure 1) [6]. $M$. 
tuberculosis within the macrophage phagosome is able to concentrate more iron from transferrin than the nonpathogenic M. smegmatis [15]. Mycobactins are also able to acquire iron from cytoplasmic pools supplied by holotransferrin [19] and from hololactoferrin, which is more available at the pulmonary infectious site than is holotransferrin [20,21]. In a recent study [22], gallium-loaded lipophilic mycobactin J from M. paratuberculosis (a surrogate for ferric-mycobactin J and structurally close to mycobactin T) was added exogenously to macrophages and was found to (1) equilibrate throughout infected and even surrounding cells and distribute between macrophage aqueous and membrane domains; (2) scavenge both holotransferrin-released and cytoplasmic iron; and (3) be recruited as Fe-mycobactin to lipid droplets delivered through lipid trafficking to Escherichia coli-containing phagosomes. Although these results are interesting, the exogenous addition of mycobactin does not mimic the in vivo situation, nor does an E. coli-infected phagosome mimic an M. tuberculosis-infected phagosome. In summary, M. tuberculosis appears to evade host defense by preventing phagosome acidification and lysosome fusion, to acquire iron from host endosomal holotransferrin, and-if confirmed-to utilize host lipid trafficking for the delivery of additional iron by mycobactin.

Effect of modifying iron status on $\mathrm{M}$. tuberculosis growth. Adding iron experimentally has always — with a single exception [23] — resulted in enhanced M. tuberculosis growth, both in vitro (axenic medium or macrophage infection) [2428] and in mice [29-32] (table 1). Furthermore, M. tuberculosis growth is reduced by interrupting iron availability, whether by (1) treatment with an exogenous iron chelator, such as deferoxamine $[26,30]$, sylibin [27], or a phytosiderophore [33]; (2) exposure to the endogenous iron chelators apo-transferrin [29] and apo-lactoferrin [26]; (3) the addition of an anti-TfR antibody to $M$. tuberculosisinfected macrophages [27]; or (4) incubation with gallium salts or gallium transferrin that occupy iron pathways with a metal that cannot be utilized by $M$. $t u$ berculosis [34]. Genetic studies have confirmed the importance of iron for $M$. $t u$ berculosis. First, as mentioned previously, a mutant defective in mycobactin synthesis has decreased growth in macrophages [14]. Similarly, an irtAB mutant compromised in the utilization of iron from $\mathrm{Fe}$ carboxymycobactin has also been shown to have defective growth [18]. Finally, $\beta_{2}-$ microglobulin knockout mice, given that they are iron overloaded, are more susceptible to tuberculosis (TB) than are control mice [26]. However, these mice are of questionable relevance for studying the relationship between $\mathrm{TB}$ and iron, because they also have several $\mathrm{T}$ cell deficiencies [35].

\section{HOST DEFENSE AGAINST $M$. TUBERCULOSIS}

As reviewed by others [36-38], defense against TB involves immune recognition by macrophages and dendritic cells, which leads to tumor necrosis factor (TNF) $-\alpha$ production and cooperative interaction with $\mathrm{T}$ cells, mainly $\mathrm{CD} 4^{+} \mathrm{T}$ lymphocytes and NK cells. The resulting Th1 type proinflammatory reaction includes interleukin (IL)-18, IL-12, interferon (IFN) $-\gamma$, and IL- $1 \beta$ production and is responsible

Table 1. Influence of alterations in iron status on the growth of Mycobacterium tuberculosis (MTb) both in vitro and in vivo.

\begin{tabular}{|c|c|c|}
\hline \multirow[b]{2}{*}{ Growth, conditions } & \multicolumn{2}{|c|}{$\begin{array}{l}\text { MTb growth } \\
\text { [references] }\end{array}$} \\
\hline & Enhanced & Inhibitec \\
\hline \multicolumn{3}{|l|}{ In vitro growth } \\
\hline \multicolumn{3}{|l|}{ Growth in broth or serum } \\
\hline Iron salts & [24-27] & \\
\hline Serum transferrin & & [29] \\
\hline Desferrioxamine & & [26] \\
\hline Silybin & & [27] \\
\hline Phytosiderophore & & [33] \\
\hline \multicolumn{3}{|l|}{ Growth in the macrophage } \\
\hline \multicolumn{3}{|l|}{ Murine macrophage } \\
\hline Iron salts & [28] & \\
\hline Lactoferrin & & [26] \\
\hline Anti-TfR antibody & & [26] \\
\hline Siderophore-deficient MTb mutant & & [14] \\
\hline \multicolumn{3}{|l|}{ Human macrophage } \\
\hline Iron salts & {$[27,28]$} & [23] \\
\hline Gallium-transferrin & & [34] \\
\hline irtAB mutation of $\mathrm{MTb}$ & & [18] \\
\hline \multicolumn{3}{|l|}{ In vivo growth (murine infection) } \\
\hline Iron enrichment of drinking water & [26] & \\
\hline Parenteral iron & [29-32] & \\
\hline Desferrioxamine & & {$[26,30]$} \\
\hline$\beta 2 \mu \mathrm{KO}$ mice & [26] & \\
\hline \multicolumn{3}{|l|}{$\begin{array}{l}\beta 2 \mu \mathrm{KO} \text { mice treated with (vs. untreated } \\
\quad \beta 2 \mu \mathrm{KO} \text { mice) }\end{array}$} \\
\hline Intranasal lactoferrin & & [26] \\
\hline Desferrioxamine & & {$[26]$} \\
\hline irtAB mutant of $\mathrm{MTb}$ & & {$[18]$} \\
\hline
\end{tabular}


for killing or controlling M. tuberculosis. Effector mechanisms involve reactive oxygen and nitrogen intermediates and apoptosis. Antiinflammatory cytokines such as IL-4, IL-10, and transforming growth factor- $\beta$, the latter 2 of which are produced by regulatory $\mathrm{T}\left(\mathrm{T}_{\text {reg }}\right)$ cells, suppress Th1 type responses and interfere with effector $\mathrm{T}$ cell activation.

Of $M$. tuberculosis-infected humans, $5 \%-10 \%$ develop clinical TB, whereas the majority develop latent infection characterized by quiescent $M$. tuberculosis with a strong Th1 and a possibly suppressed Th2 cytokine response [38]. Clinical TB is associated with a mixed Th1/Th2 response and Th2 dominance [38], and therapeutic recovery from TB usually involves restored Th1 dominance over Th2 [39].

\section{EFFECT OF CYTOKINES ON MACROPHAGE IRON STATUS}

IFN- $\gamma$, which is pivotal for protection against TB, also influences cellular iron status. Indeed, IFN- $\gamma$ activation of human monocytes down-regulates TfR numbers on the cell surface [40] and the rate of macrophage iron acquisition from holotransferrin [19], and it decreases iron availability to intracellular microorganisms that utilize transferrin iron, such as $L e$ gionella pneumophila [40] and M. tuberculosis, as discussed above. M. tuberculosis remains able, at least in vitro, to access other iron sources, despite the IFN- $\gamma$-induced limitation in macrophage iron acquisition [19]. Macrophage M. tuberculosis infection does not subvert this IFN- $\gamma$-induced decrease in TfR expression [19, 41].

In contrast to classical macrophage activation by bacterial products or IFN- $\gamma$, alternative macrophage activation by Th2 cytokines has 2 potential implications for macrophage iron status. First, during experimental $\mathrm{TB}$, alternatively activated mouse macrophages express the gene encoding arginase-1 [41]. Arginase-1 competition with inducible nitric oxide synthase (iNOS) for L-arginine results in decreased NO production and, hence, possibly less iron efflux [42] and more iron being available to M. tuberculosis. Whether the differential expression of arginase-1 versus iNOS applies to humans is unclear. Second, alternative activation of uninfected macrophages results in increased expression of both TfR and CD163, resulting in increased TfR-related and CD163-mediated iron acquisition [41, 43]. Furthermore, in a comparative gene-expression study of M. tuberculosis-infected murine macrophages activated by either IL- 4 or IFN- $\gamma$, IL-4 led to increases in both host TfR expression and M. tuberculosis iron availability as manifested by decreased mycobactin and increased bacterioferritin synthesis, whereas IFN- $\gamma$ was associated with opposite findings [41]. Whether these interesting experimental results apply to human M. tuberculosis infection is speculative. The fact that serum ferritin levels increased in a dose-dependent manner during recombinant human IL-10 treatment of patients with Crohn disease (evidence grade 1) [44] is consistent with the concept that immunosuppressive cytokines increase macrophage iron availability.

\section{EFFECT ON TB OF CONDITIONS THAT MAY AUGMENT RETICULOENDOTHELIAL IRON STORES}

In some conditions, reticuloendothelial iron loading originates from the alimentary tract, the respiratory route, or hemolysis, whereas, in others, it results from chronic inflammation. The administration of iron-dextran to rats results in bronchoalveolar macrophage iron loading [45]. Hence, it is conceivable that human ironloading conditions might enhance $M$. $t u$ berculosis growth in alveolar macrophages. Iron loading affects the immune system in a way that resembles alternative macrophage activation. When erythropoietin-treated patients undergoing hemodialysis were randomized to receive or not receive intravenous iron, those receiving iron developed lower TNF- $\alpha$ but higher
IL-4 serum concentrations (evidence grade 1) [46]. In volunteers receiving $120 \mathrm{mg}$ of oral iron daily for 7 days, IL-4 serum levels increased modestly but significantly [47].

Some clinical conditions characterized by generalized or local reticuloendothelial iron loading are possibly associated with TB. In African iron overload and in HIV/ AIDS, the available evidence suggests a pathophysiological role of iron loading that increases the risk of TB or worsens its outcome. In other conditions that increase the risk of TB and/or worsen its outcome (e.g., tobacco smoking and alcoholism), there is some degree of iron loading, but its pathogenetic role is hypothetical; in human malaria, another condition with increased macrophage iron, the association with $\mathrm{TB}$, is conjectural. Although inconclusive, data on tobacco smoking, alcoholism, and malaria are presented as basis of future research.

African iron overload. Iron overload of both macrophages and hepatocytes is common in sub-Saharan African populations drinking a traditional beverage of high iron content that is brewed in nongalvanized steel containers. In addition to high dietary iron, a non-HFE genetic defect may be implicated in iron loading [48]. African iron overload was first described in autopsies performed in the 1920s on black Africans whose cause of death was recorded, and hepatic, splenic, and lymph-node iron was graded on a scale of 1-5. When these data were reanalyzed in the 1990s, splenic (macrophage) iron was the variable most significantly associated with death from TB-the odds of death from TB were 16.9-fold higher in persons with the highest, compared with the 2 lowest, grades of splenic iron (evidence grade 2) [49]. In a prospective study of the relationship between pulmonary TB and increased dietary iron (lifetime consumption of traditional beer) among 98 Zimbabwean patients with pulmonary TB and 98 control subjects, increased dietary iron was associated with a 3.5-fold increase in the estimated odds of developing pulmonary $\mathrm{TB}$ and with 
a trend toward higher mortality among the patients with pulmonary TB (evidence grade 2) [50].

HIV/AIDS. The HIV epidemic dramatically fuels the coexisting TB epidemic. Macrophage iron loading in the setting of HIV may be due to blood transfusion or to HIV- and opportunistic infection-induced inflammation [51], which would be expected to lead to hepcidin production and macrophage iron trapping. HIV may also contribute to macrophage iron loading by its Nef protein, which interacts with HFE, the protein mutated in classical hereditary hemochromatosis, and markedly decreases its expression on the surface of macrophages. The net effect of this interaction is to increase macrophage iron and ferritin content [52]. Macrophage iron loading during HIV infection may increase oxidative stress and lower intracellular glutathione levels, impairing the antiTB defense. Indeed, (nitroso-)glutathione inhibits M. tuberculosis growth in vitro, whereas the glutathione precursor $\mathrm{N}$-acetyl cysteine improves control of intracellular M. tuberculosis cultured in blood from HIV-infected patients [53]. Clinical studies of the adverse influence of high iron stores on the outcome of HIV infection have been reviewed elsewhere [54]. One retrospective study of bone-marrow macrophage iron grades in HIV-seropositive patients found significantly more frequent $\mathrm{TB}$ in patients with high, compared with low or normal, macrophage iron grades (evidence grade 3) [55]. The impact of HIV-related macrophage iron loading on TB requires more investigation.

Tobacco smoking. Tobacco smoking is a major risk factor for pulmonary but not extrapulmonary TB infection and death, which implicates a local airborne insult [56]. A parasympathetic antiinflammatory pathway has been identified, whereby activation of macrophage $\alpha 7$ nicotinic acetylcholine receptors in bronchoalveolar macrophages reduces the synthesis and release of TNF- $\alpha$, IL-1, and IL-6 [57]. Because nicotine is an agonist of these receptors, tobacco smoking should inhibit alveolar macrophage TNF- $\alpha$ release, impairing the formation of appropriate $M$. tuberculosis-containing granulomas. Tobacco smoking may also favor TB by iron loading alveolar macrophages, given that smoking 1 pack of cigarettes is equivalent to inhaling $1.1 \mu \mathrm{g}$ of iron [58]. Iron levels in alveolar macrophages are 2-fold higher in asymptomatic smokers and 4.6-7-fold higher in symptomatic smokers than in nonsmokers. Proof that tobacco smoking increases the risk of TB by loading the alveolar macrophages with iron is lacking at present.

Alcoholism. In a cross-sectional study in humans [59], alcoholism was the strongest predictor of TB in tobacco smokers, with an adjusted odds ratio of 7.4 (evidence grade 2). Alcoholism may result in alimentary iron loading because ethanol metabolism down-regulates hepcidin expression [60]. Among 8839 individuals who did not consume alcohol or who had consumed $<1,1-2$, or $>2$ daily alcoholic drinks during the preceding year, serum transferrin saturation and ferritin levels were significantly higher in consumers of $>2$ daily alcoholic drinks, compared with nonconsumers, after adjustment for potential confounders [61]. After 2 weeks of alcohol consumption, mice had decreased lymphocyte proliferation and IFN- $\gamma$ production, smaller granulomas, and higher M. tuberculosis lung burdens than control mice [62]. At the bronchoalveolar level, chronic alcoholism suppresses Th1 and induces $\mathrm{T}_{\text {reg }}$ cells responses [63], potentially enhancing the risk of $\mathrm{TB}$, but it is unknown whether human alcoholism may favor TB by inducing alveolar macrophage iron loading. In one study, chronic alcohol exposure of rats did not increase iron levels in alveolar macrophages, in agreement with alcohol-induced down-regulation of hepcidin, but the sample size was limited [64].

Malaria. In most reports, a Th1-biased response clears an uncomplicated acute human Plasmodium falciparum infection [65]. Malaria suppresses the immune response to both parasite and non- parasite antigens, probably because of macrophage accumulation of hemozoin, a hematin (ferri-protoporphyrin IX) polymer derived from hemoglobin ingested by intraerythrocytic plasmodia [66]. Hemozoin-fed human monocyte-derived macrophages produce IL-10 in a dose-dependent manner [67] and show impaired differentiation to mature dendritic cells [67], and $\mathrm{T}$ cells activated by these dendritic cells lack effector functions [68]. $M$. tuberculosis-infected mice coinfected later with $P$. yoelii have higher organ M. tuberculosis burdens than mice infected only with M. tuberculosis and have higher mortality than mice infected only with $M$. tuberculosis or P. yoelii. Hemozoin-related lung and liver pigmentation is stronger in coinfected mice than in those infected only with plasmodium species, which suggests that there is more malarial hemolysis-induced iron loading that favors $M$. tuberculosis growth in coinfected mice [69]. At present, it is unclear whether malaria affects the development or outcome of human TB.

\section{IRON-RELATED GENES AND HUMAN TUBERCULOSIS}

Hereditary iron overload. In classical hereditary hemochromatosis caused by homozygosity for the $\mathrm{C} 282 \mathrm{Y}$ mutation of HFE, alimentary iron overabsorption results in iron loading of liver, heart, and pancreas parenchymal cells, whereas macrophages are relatively iron deficient. In M. tuberculosis-infected macrophages from patients with hemochromatosis, intraphagosomal M. tuberculosis acquires less iron from holotransferrin and is $50 \%$ growthretarded, compared with that in normal macrophages [19, 21]. Studies to confirm whether patients with hemochromatosis have a lower risk of TB have not been reported. M. tuberculosis has been hypothesized to exert a selective pressure responsible for a high prevalence of HFE mutations in certain populations (evidence grade 3) [70]. By contrast, ferroportin 1 mutations often result in macrophage iron loading [71]. Whether they may increase 
the risk of TB is unknown. Salmonella enterica growth is reduced by macrophage ferroportin 1 expression and increased by its hepcidin-induced down-regulation [72], which is compatible with the suggestion that a ferroportin 1 mutation also might increase TB susceptibility.

Hp. Binding of hemoglobin-Hp to the monocyte/macrophage CD163 results in internalization of heme and, eventually, to heme degradation and IL-10 secretion [73]. There are $3 \mathrm{Hp}$ phenotypes: Hp 11, Hp 1-2, and Hp 2-2. Multimeric Hp 22 , which has a 10 -fold higher CD136 affinity than $\mathrm{Hp} 1-1$, may result in greater macrophage iron acquisition [4] and increased serum markers of iron loading, as has been observed in some but not all studies (reviewed in [74]), as well as more macrophage IL-10 production. In the previously mentioned study of Zimbabwean patients with pulmonary TB and control subjects [50], the Hp phenotype did not modulate TB susceptibility, but it did affect treatment outcome; the odds of death were 6.1-fold higher in patients with TB carrying Hp 2-2, compared with those carrying Hp 1-1 [75]. It is uncertain whether this worse TB outcome in individuals carrying Hp 2-2 relates to differences in iron status.

NRAMP1. NRAMP1, the gene product of NRAMP1 (SLC11A1), is principally expressed in the membranes of late endosomes, phagosomes, and lysosomes of macrophages. In mice, NRAMP1 activates an early microbicidal mechanism that provides resistance to several intracellular microorganisms, including M. avium and $M$. bovis (bacille Calmette-Guérin [BCG]) but not M. tuberculosis. A G169D substitution renders NRAMP1 nonfunctional, causing murine susceptibility to these infections. NRAMP1 transports divalent cations (putatively iron) across the phagosomal membrane, but opposing views exist on the flux direction: either $\mathrm{Fe}^{2+}$ influx into the bacterium-containing phagosome causes bacterial killing by forming reactive oxygen species [76], or, because macrophages without functional NADPH oxidase have their resistance unaffected [77], $\mathrm{Fe}^{2+}$ efflux restricts bacterial growth by iron deprivation $[77,78]$. The latter view is gaining more experimental support (figure 1) [79]. The G169D mutation in human NRAMP1 has never been found, but there are several NRAMP1 polymorphisms in the noncoding human gene regions.

Fourteen studies examining the relationship between human NRAMP1 polymorphisms and TB susceptibility were analyzed in a meta-analysis that involved 2460 case patients and 3227 control subjects and covered the 4 most investigated NRAMP1 polymorphisms [80]. The odds ratio of TB with the $3^{\prime}$ untranslated region (UTR) variant was 1.33 , that with the D543N variant was 1.67 , that with the INT4 variant was 1.14 , and that with the $5^{\prime}(\mathrm{GT}) \mathrm{n}$ variants was 1.32 , compared with the corresponding common alleles. Polymorphisms at these 4 loci significantly increased the risk of pulmonary TB in Africans (except the $3^{\prime}$ UTR) and in Asians (except INT4) but not in white persons, whose numbers were low (evidence grade 2 ). More data are needed about the direction of the NRAMP1-associated iron flux and the effect of NRAMP1 polymorphisms on TB susceptibility.

\section{ANTITUBERCULAR THERAPY AND IRON}

$p$-aminosalicylic acid inhibits the conversion of salicylate to (carboxy-)mycobactin and therefore targets $M$. tuberculosis iron acquisition [13]. The prodrug isoniazid needs conversion to an active form that inhibits mycolic acid biosynthesis. This conversion requires the heme-containing catalase peroxidase, which is encoded by the $M$. tuberculosis kat $G$ gene and protects $M$. tuberculosis against oxidative damage [81]. In a study of the effect of experimental iron loading on the therapeutic efficacy of isoniazid in murine high-inoculum TB infection [32], the bactericidal activity of isoniazid was significantly reduced in iron-loaded compared with normal-iron mice, because of either the growth-promoting or immunological ef- fects of iron or the massive oxidative stress overwhelming the kat $G$-associated protection against reactive oxygen species.

\section{ANTITUBERCULAR VACCINATION AND IRON}

BCG vaccination is of low efficacy in persons in developing tropical and subtropical areas, who also face helminth infections, environmental mycobacteria, malaria, HIV, and malnutrition-conditions that may suppress Th1 and enhance $\mathrm{Th} 2 / \mathrm{T}_{\text {reg }}$ cell responses [38]. It seems possible that an increased macrophage iron burden may be one of the mechanisms exacerbating immune dysregulation and BCG vaccine failure. We suggest that iron status should be taken into account in further studies of anti-M. tuberculosis vaccines. For instance, one could (1) compare results of vaccinating animals fed an ironpoor versus iron-enriched diet and (2) test the administration of apolactoferrin together with new TB vaccines, given that apolactoferrin coadministration enhances delayed-type hypersensitivity toward BCG in mice [82] and increases the efficacy of BCG in protecting mice against virulent M. tuberculosis [83]. It is uncertain whether this beneficial lactoferrin effect relates to iron binding, immunological effects, or antibacterial activity of its breakdown peptide, lactoferricin.

\section{RESEARCH PROSPECTS}

In view of the critical importance of iron in TB pathogenesis, research might be directed at examining the effect of manipulating several stages of the iron pathways of the host and the invading organism: (1) the quantity of iron entering the host via the alimentary, parenteral, and respiratory routes; (2) the amount of hepcidin circulating in the host; (3) the function of ferroportin 1, the hepcidin receptor, at the host macrophage membrane; (4) the direction of iron flux by NRAMP1 at the host phagosomal membrane; (5) host phagosomal maturation and acidification; (6) mycobactin synthesis by $M$. tuberculosis; and (7) the ferric mycobactin trans- 
port pathway of M. tuberculosis. Furthermore, research on M. tuberculosis and iron may result in spin-offs into unrelated fields. For example, iron-free mycobactin reversibly blocks the in vitro growth of vascular smooth-muscle cells because its iron-chelating properties block redoxmodulated signaling pathways and several enzymes. One clinical situation where blocking the proliferation of these cells might be desirable is the prevention of coronary restenosis after coronary balloon angioplasty. Intramural application of mycobactin shortly after coronary balloon injury, tested in a porcine model, halved the injury score and reduced neointima thickness [84]. Results in humans are awaited.

\section{CONCLUSION}

Trousseau reported in 1872 [85] that patients recovering from active TB had a relapse if they received iron-rich supplements, and he warned against their use. The relationship between iron and TB is now strengthened thanks to the elucidation of the M. tuberculosis genome, advances in immunology, and clinical study results. Drugs that target mycobacterial iron-acquisition pathways or host pathways that affect iron availability for $M$. tuberculosis are worth developing and testing for anti-TB activity. The role of iron should be taken into account in future vaccine studies.

\section{References}

1. Hentze MW, Muckenthaler MU, Andrews NC. Balancing acts: molecular control of mammalian iron metabolism. Cell 2004; 117 : 285-97.

2. Nemeth E, Tuttle MS, Powelson J, et al. Hepcidin regulates cellular iron efflux by binding to ferroportin and inducing its internalization. Science 2004; 306:2090-3.

3. Suzuki YA, Lopez V, Lonnerdal B. Mammalian lactoferrin receptors: structure and function. Cell Mol Life Sci 2005; 62:2560-75.

4. Kristiansen M, Graversen JH, Jacobsen C, et al. Identification of the haemoglobin scavenger receptor. Nature 2001; 409:198-201.

5. Theurl I, Mattle V, Seifert M, Mariani M, Marth C, Weiss G. Dysregulated monocyte iron homeostasis and erythropoeitin forma- tion in patients with the anemia of chronic disease. Blood 2006; 107:4142-8.

6. Clemens DL, Horwitz MA. The Mycobacterium tuberculosis phagosome interacts with early endosomes and is accessible to exogenously administered transferrin. J Exp Med 1996; 184:1349-55.

7. Mwandumba HC, Russell DG, Nyirenda MH, et al. Mycobacterium tuberculosis resides in nonacidified vacuoles in endocytically competent alveolar macrophages from patients with tuberculosis and HIV infection. J Immunol 2004; 172:4592-8.

8. Schnappinger D, Ehrt S, Voskuil MI, et al. Transcriptional adaptation of Mycobacterium tuberculosis within macrophages: insight into the phagosomal environment. J Exp Med 2003; 198:693-704.

9. Appelberg R. Macrophage nutriprive antimicrobial mechanisms. J Leukoc Biol 2006; 79: 1117-28.

10. Weinberg ED. Iron withholding: a defense against infection and neoplasia. Physiol Rev 1984; 64:65-102.

11. Dubnau E, Chan J, Mohan VP, Smith I. Responses of Mycobacterium tuberculosis to growth in the mouse lung. Infect Immun 2005; 73: 3754-7.

12. Timm J, Post FA, Bekker L-G, et al. Differential expression of iron-, carbon-, and oxygen-responsive mycobacterial genes in the lungs of chronically infected mice and tuberculosis patients. Proc Natl Acad Sci USA 2003; 100:14321-6.

13. Ratledge C. Iron, mycobacteria and tuberculosis. Tuberculosis 2004; 84:110-30.

14. De Voss JJ, Rutter K, Schroeder BJ, Su H, Zhu Y, Barry CE. The salicylate-derived mycobactin siderophores of Mycobacterium tuberculosis are essential for growth in macrophages. Proc Natl Acad Sci USA 2000; 97:1252-7.

15. Wagner D, Maser J, Lai B, et al. Elemental analysis of Mycobacterium avium-, Mycobacterium tuberculosis- and Mycobacterium smegmatis-containing phagosomes indicates pathogen-induced microenvironments within the host cell's endosomal system. J Immunol 2005; 174:1491-500.

16. Gold B, Rodriguez GM, Marras SAE, Pentecost M, Smith I. The Mycobacterium tuberculosis Ide is a dual functional regulator that controls transcription of genes involved in iron acquisition, iron storage and survival in macrophages. Mol Microbiol 2001; 42:851-65.

17. Rodriguez GM, Voskuil MI, Gold B, Schoolnik GK, Smith I. ideR, an essential gene in $M y$ cobacterium tuberculosis: role of IdeR in irondependent gene expression, iron metabolism, and oxidative stress response. Infect Immun 2002; 70:3371-81.

18. Rodriguez GM, Smith I. Identification of an $\mathrm{ABC}$ transporter required for iron acquisition and virulence in Mycobacterium tuberculosis. J Bacteriol 2006; 188:424-30.

19. Olakanmi O, Schlesinger LS, Ahmed A, Britigan BE. Intraphagosomal Mycobacterium tuberculosis acquires iron from both extracellular transferrin and intracellular pools: impact of interferon $-\gamma$ and hemochromatosis. J Biol Chem 2002; 277:49727-34.

20. Olakanmi O, Schlesinger LS, Ahmed A, Britigan BE. The nature of extracellular iron influences iron acquisition by Mycobacterium tuberculosis residing within human macrophages. Infect Immun 2004; 72:2022-8.

21. Olakanmi O, Schlesinger LS, Britigan BE. Hereditary hemochromatosis results in decreased iron acquisition and growth by Mycobacterium tuberculosis within human macrophages. J Leukoc Biol 2007; 81:195-204.

22. Luo M, Fadeev EA, Groves JT. Mycobactinmediated iron acquisition within macrophages. Nat Chem Biol 2005; 1:149-53.

23. Byrd TF. Tumor necrosis factor $\alpha(\mathrm{TNF} \alpha)$ promotes growth of virulent Mycobacterium tuberculosis in human monocytes: iron-mediated growth suppression is correlated with decreased release of TNF- $\alpha$ from iron-treated monocytes. J Clin Invest 1997; 99:2518-29.

24. Youdim S. In vitro effect of iron salts and chelating agents on serum tuberculostasis. Am Rev Resp Dis 1969; 99:925-31.

25. Raghu B, Raghupati S, Venkatesan P. Effect of iron on the growth and siderophore production of mycobacteria. Biochem Mol Biol Int 1993; 31:341-8.

26. Schaible UE, Collins HL, Priem F, Kaufmann SHE. Correction of the iron overload defect in $\beta$-2-microglobulin knockout mice by lactoferrin abolishes their increased susceptibility to tuberculosis. J Exp Med 2002; 196:1507-13.

27. Cronjé L, Edmondson N, Eisenach KD, Bornman L. Iron and iron-chelating agents modulate Mycobacterium tuberculosis growth and monocyte-macrophage viability and effector functions. FEMS Immunol Med Microbiol 2005; 45:103-12.

28. Rook GA, Steele J, Ainsworth M, Champion BR. Activation of macrophages to inhibit proliferation of Mycobacterium tuberculosis: comparison of the effects of recombinant gammainterferon on human monocytes and murine peritoneal macrophages. Immunology 1986; 59:333-8.

29. Kochan I. The role of iron in bacterial infections, with special consideration of host-tubercle bacillus interaction. Curr Top Microbiol Immunol 1973; 60:1-30.

30. Lounis N, Maslo C, Boelaert JR, et al. Impact of iron loading on murine tuberculosis. Clin Microbiol Infect 1999; 5:687-92.

31. Lounis N, Truffot-Pernot C, Grosset J, Gordeuk VR, Boelaert JR. Iron and Mycobacterium tuberculosis infection. J Clin Virol 2001;20: 123-6.

32. Lounis N, Maslo C, Truffot-Pernot C, Grosset J, Boelaert JR. Impact of iron loading on the activity of isoniazid or ethambutol in the treatment of murine tuberculosis. Int J Tuberc Lung Dis 2003; 7:575-9.

33. Rajiv J, Dam T, Kumar S, Bose M, Aggarwal $\mathrm{KK}$, Babu CR. Inhibition of the in-vitro growth of Mycobacterium tuberculosis by a 
phytosiderophore. J Med Microbiol 2001; 50: 916-8.

34. Olakanmi O, Britigan BE, Schlesinger LS. Gallium disrupts iron metabolism of mycobacteria residing within human macrophages. Infect Immun 2000; 68:5619-27.

35. Schaible UE, Kauffmann SHE. Iron and microbial infection. Nat Rev Microbiol 2004; 2: 946-53.

36. Flynn J, Chan J. Immunology of tuberculosis. Annu Rev Immunol 2001; 19:93-129.

37. Van Crevel R, Ottenhoo THM, van der Meer JWM. Innate immunity to Mycobacterium tuberculosis. Clin Microbiol Rev 2002; 15:294-309.

38. Rook GAW, Dheda K, Zumla A. Immune response to tuberculosis in developing countries: implications for new vaccines. Nat Rev Immunol 2005; 5:661-7.

39. Adams JFA, Schölvinck EH, Gie RP, Potter PC, Beyers N, Beyers AD. Decline in total serum IgE after treatment for tuberculosis. Lancet 1999; 353:2030-2.

40. Byrd TF, Horwitz MA. Interferon-gammaactivated human monocytes downregulate transferrin receptors and inhibit the intracellular multiplication of Legionella pneumophila by limiting the availability of iron. J Clin Invest 1989; 83:1457-65.

41. Kahnert A, Seiler P, Sein M, et al. Alternative activation deprives macrophages of a coordinated defense program to Mycobacterium tuberculosis. Eur J Immunol 2006; 36:631-47.

42. Mulero V, Wei XQ, Liew FY, Brock JH. Regulation of phagosomal iron release from murine macrophages by nitric oxide. Biochem J 2002; 365:127-32.

43. Mosser DM. The many faces of macrophage activation. J Leukoc Biol 2003; 73:209-12.

44. Tilg H, Ulmer H, Kaser A, Weiss G. Role of IL-10 for induction of anemia during inflammation. J Immunol 2002; 169:2204-9.

45. Leggsyer R, Ward RJ, Crichton RR, Boelaert JR. Effect of chronic chloroquine administration on iron loading in the liver and reticuloendothelial system and on oxidative responses by the alveolar macrophages. Biochem Pharmacol 1999; 57:907-11.

46. Weiss G, Meusburger E, Radacher G, Garimorth K, Neyer U, Mayer G. Effect of iron treatment on circulating cytokine levels in ESRD patients receiving recombinant human erythropoietin. Kidney Int 2003; 64:572-8.

47. Schümann K, Kroll S, Weiss G, et al. Monitoring of hematological, inflammatory and oxidative reactions to acute oral iron exposure in human volunteers: preliminary screening for selection of potentially-responsive biomarkers. Toxicology 2005; 212:10-23.

48. Gordeuk VR. African iron overload. Semin Hematol 2002; 39:263-9.

49. Gordeuk VR, McLaren CE, MacPhail AP, Deichsel G, Bothwell TH. Associations of iron overload in Africa with hepatocellular carcinoma and tuberculosis: Strachan's 1929 thesis revisited. Blood 1996; 87:3470-6.

50. Gangaidzo IT, Moyo VM, Mvundura E, et al. Association of pulmonary tuberculosis with increased dietary iron. J Infect Dis 2001; 184: 936-9.

51. Boelaert JR, Weinberg GA Weinberg ED. Altered iron metabolism in HIV infection: mechanisms, possible consequences, and proposals for management. Infect Agents Dis 1996; 5:36-46.

52. Drakesmith $\mathrm{H}$, Chen $\mathrm{N}$, Ledermann $\mathrm{H}$, Screaton G, Towsend A, Xu XN. HIV-1 Nef downregulates the hemochromatosis protein HFE, manipulating cellular iron homeostasis. Proc Natl Acad Sci USA 2005; 102:11017-22.

53. Venketaraman $V$, Rodgers $T$, Linares $R$, et al. Glutathione and growth inhibition of $\mathrm{Myco}$ bacterium tuberculosis in healthy and HIV-infected subjects. AIDS Res Ther 2006; 3:5.

54. Gordeuk VR, Delanghe JR, Langlois MR, Boelaert JR. Iron status and the outcome of HIV infection: an overview. J Clin Virol 2001;20: 111-5.

55. De Monyé C, Karcher DS, Boelaert JR, Gordeuk VR. Bone marrow macrophage iron grade and survival of HIV-seropositive patients. AIDS 1999; 13:375-80.

56. Leung CC, Li T, Lam TH, et al. Smoking and tuberculosis among the elderly in Hong Kong. Am J Respir Crit Care Med 2004; 170:1027-33.

57. Wang $\mathrm{H}$, $\mathrm{Yu} \mathrm{M}$, Ochani $\mathrm{M}$, et al. Nicotinic acetylcholine receptor $\alpha 7$ unit is an essential regulator of inflammation. Nature 2003; 421: 384-8.

58. Boelaert JR, Gomes MS, Gordeuk VR. Smoking, iron and tuberculosis. Lancet 2003; 362: 1243-4.

59. Altet-Gomez MN, Alcaide J, Godoy P, Romero MA, Hernandez del Rey I. Clinical and epidemiological aspects of smoking and tuberculosis: a study of 13038 cases. Int J Tuberc Lung Dis 2005; 9:430-6.

60. Harrison-Findik DD, Schafer D, Klein E, et al. Alcohol metabolism-mediated oxidative stress down-regulates hepcidin transcription and leads to increased duodenal iron transporter expression. J Biol Chem 2006; 281:22974-82.

61. Iannou GN, Dominitz JA, Weiss NS, Heagerty PJ, Kowdey KV. The effect of alcohol consumption on the prevalence of iron overload, iron deficiency, and iron deficiency anemia. Gastroenterology 2004; 126:1293-301.

62. Mason CM, Dobard E, Zhang P, Nelson S. Alcohol exacerbates murine pulmonary tuberculosis. Infect Immun 2004; 72:2556-63.

63. Crews FT, Bechara R, Brown LA, et al. Cytokines and alcohol. Alcohol Clin Exp Res 2006; 30:720-30.

64. Zhang Y, Crichton RR, Boelaert JR, et al. Decreased release of nitric oxide $(\mathrm{NO})$ by alveolar macrophages after in vivo loading of rats with either iron or ethanol. Biochem Pharmacol 1998; 55:21-5.

65. Urban BC, Ing R, Stevenson MM. Early interactions between blood-stage plasmodium parasites and the immune system. Curr Top Microbiol Immunol 2005; 297:25-70.

66. Deshpande P, Shastry P. Modulation of cytokine profiles by malaria pigment-hemozoin: role of IL-10 in suppression of proliferative responses of mitogen stimulated human PBMC. Cytokine 2004; 28:205-13.

67. Skorokhod OA, Alessio M, Mordmüller B, Arese P, Schwarzer E. Hemozoin (malarial pigment) inhibits differentiation and maturation of human monocyte-derived dendritic cells: a peroxisome proliferator-activated receptor- $\gamma$ mediated effect. J Immunol 2004; 173:4066-74.

68. Millington OR, Di Lorenzo C, Phillips RS, Garside P, Brewer JM. Suppression of adaptive immunity to heterologous antigens during Plasmodium infection through hemozoin-induced failure of dendritic cell function. J Biol 2006; 5:5-22.

69. Scott CP, Kumar N, Bishai WR, Manabe YC. Modulation of Mycobacterium tuberculosis infection by Plasmodium in the murine model. Am J Trop Med Hyg 2004; 70:144-8.

70. Moalem S, Weinberg ED, Percy ME. Hemochromatosis and the enigma of misplaced iron: implications for infectious disease and survival. Biometals 2004; 17:135-9.

71. Pietrangelo A. The ferroportin disease. Blood Cells Mol Dis 2004; 32:131-8.

72. Chlosta S, Fishman DS, Harrington L, et al. The iron efflux ferroportin regulates the intracellular growth of Salmonella enterica. Infect Immun 2006; 74:3065-7.

73. Philippidis P, Mason JC, Evans BJ, et al. Hemoglobin scavenger CD163 mediates interleukin-10 release and heme oxygenase-1 synthesis: anti-inflammatory monocyte-macrophage responses in vitro, in resolving skin blisters in vivo, and after cardiopulmonary bypass surgery. Circ Res 2004; 94:119-26.

74. McDermid JM, Prentice AM. Iron and infection: effects of host iron status and the ironregulatory genes haptoglobin and NRAMP1 (SLC11A1) on host-pathogen interactions in tuberculosis and HIV. Clin Sci 2006; 110 : 503-24.

75. Kasvosve I, Gomo ZAR, Mvundura E, et al. Haptoglobin polymorphism and mortality in patients with tuberculosis. Int J Tuberc Lung Dis 2000; 4:1-5.

76. Zwilling BS, Kuhn DE, Wikoff L, Brown D, Lafuse W. Role of iron in Nramp1-mediated inhibition of mycobacterial growth. Infect Immun 1999; 67:1386-92.

77. Gomes MS, Appelberg R. NRAMP1- or cytokine-induced bacteriostasis of Mycobacterium avium by mouse macrophages is independent of the respiratory burst. Microbiology 2002; 148:3155-60.

78. Gomes MS, Appelberg R. Evidence for a link between iron metabolism and NRAMP 1 gene function in innate resistance against Mycobacterium avium. Immunology 1998; 95:165-8.

79. Jabado N, Cuellar-Mata P, Grinstein S, Gros P. Iron chelators modulate the fusogenic properties of Salmonella-containing phagosomes. Proc Natl Acad Sci USA 2003; 100:6127-32.

80. Li HT, Zhang TT, Zhou YQ, Huang QH, Huang J. SLCA1 (formerly NRAMP1) gene polymorphisms and tuberculosis susceptibil- 
ity: a meta-analysis. Int J Tuberc Lung Dis 2006; 10:3-12.

81. Dussurget O, Smith I. Interdependence of mycobacterial iron regulation, oxidative-stress response and isoniazid resistance. Trends Microbiol 1998; 6:354-8.

82. Zimecki M, Kruzel ML. Systemic or local coadministration of lactoferrin with sensitizing dose of antigen enhances delayed type hyper- sensitivity in mice. Immunol Lett 2000; 74 183-8.

83. Hwang SA, Kruzel ML, Actor JK. Lactoferrin augments BCG vaccine efficacy to generate $T$ helper response and subsequent protection against challenge with virulent Mycobacterium tuberculosis. Int Immunopharmacol 2005; 5: 591-9.

84. Rosenthal EA, Bohlmeyer TJ, Monnet E, et al.
An iron-binding exochelin prevents restenosis due to coronary artery balloon injury in a porcine model. Circulation 2001; 104:2222-7.

85. Trousseau A. True, false chlorosis. In: Lectures on clinical medicine. London: The New Sydenham Society, 1872; 5:95-117. 